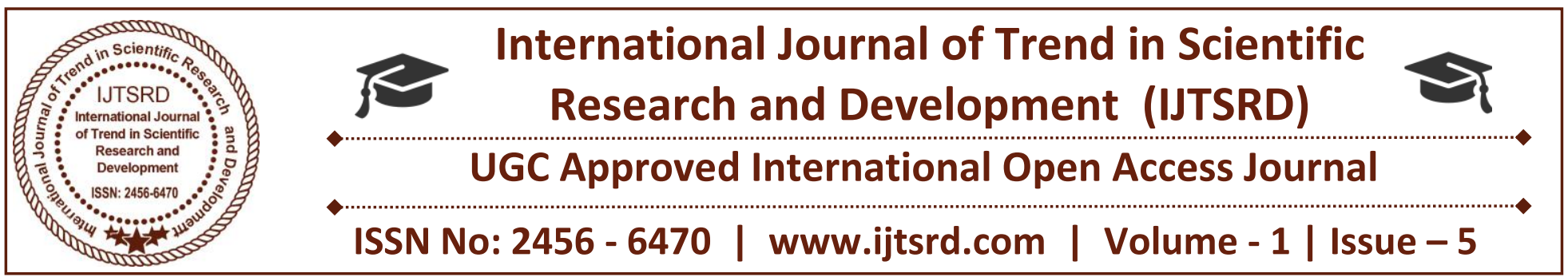

\title{
A Reiew on Different Configurations and Control Strategies for PMSG based WECS
}

\author{
Anita \\ M.Tech Scholar, Electrical Engineering Department \\ RPIIT, Karnal, India
}

\author{
Satish Kumar \\ Professor, Electrical engineering Department \\ RPIIT, Karnal, India
}

\begin{abstract}
The increasing trends in wind energy technology are motivating the researchers to work in this area with the aim towards the optimization of the energy extraction from the wind and the injection of the quality power into the grid. Over the last few years, wind generators based on permanent magnet synchronous generators (PMSGs) are becoming the more popular solution for the modern wind energy conversion systems (WECSs). This paper presents a critical review of the grid-integrated WECSs employing permanent magnet synchronous generators (PMSGs). It reviews the trends in different configurations, converter topologies, control methodologies, and methods for maximum energy extraction in PMSG based WECSs, which have been reported in various research literatures primarily in reputed research journals and transactions during last few years.
\end{abstract}

Keywords: Wind energy conversion system; Power electronics based converters; Wind turbine;

\section{INTRODUCTION}

In renewable power generation the wind energy has been noted as the most swiftly growing technology with the development in megawatts capacity wind turbines, large power generators and power electronics. It draws interest as one of the most money spinning ways to generate electricity from renewable sources. The clean energy sources such as solar, tidal and wind energy sources are gaining importance due to their less damaging environmental influences. The wind energy technology is one of the most emerging renewable energy technologies. Over the past few decades, the capacities of wind turbine (WT) units have increased from a few tens of $\mathrm{kW}$ power capacity to today's multi-MW level. In view to the steady growth in the power level of the WTs and its increased penetration into the power grid; more advanced generators, power converter systems and control solutions have to be developed so as to make the WT units more suitable to be integrated into the power grid [1, 2]. Any WT generator may operate either at a fixed or variable speed [3, 4]. For instance, the squirrel cage induction generators (SCIGs) can be employed both in fixed-speed wind turbines (FSWTs) and in variable-speed wind turbines (VSWTs), while doubly-fed induction generators (DFIGs) and synchronous generators (SGs) usually find their applications in VSWTs [3]. An overview of possible wind generator systems along with their comparisons is presented in $[3,4]$. A fixed-speed SCIG based WECS, even though is simple, reliable and less costly; strictly suffers from the shortcomings of high mechanical stress, reactive power burden on power grid, large power fluctuations and very limited faultride-through (FRT) ability [5]. When compared with FSWT, the VSWT can extract maximum power from the wind at different wind speeds and therefore, reduces the mechanical stress on WT by absorbing the wind-power fluctuations [6]. Recently, voltage source converter (VSC) based permanent magnet generator (PMSG) wind turbine is assessed to be higher ranked than doubly fed induction generator (DFIG) wind turbine in terms of reliability and efficiency. The variable speed wind turbine with a direct drive multi 
pole PMSG with fully controllable voltage source converters is catching market progressively specially in offshore applications. Among the various power electronics topologies used in wind energy conversion system, the most promising one is permanent magnet synchronous generator (PMSG) with a full-scale back-to-back power converter [1,2].

The basic components in WECS include variable speed wind turbine, aerodynamic converter, an electric generator and power electronic interface. Wind energy conversion system is interfaced with the utility system through power electronic converters. Various power electronics interfaces are used in WECS to convert generator output power to suitable form. Controlled rectifiers and inverters with various inverter switching schemes have been used in modern wind turbines $[3,4]$. Each of them has its own relative merits and demerits. The main issue in the converter based grid connected wind energy conversion system is fluctuation of voltage and harmonic distortion [5]. It is very important to assure that the grid is capable of staying within the operational limits of voltage and frequency for all expected combination of WECS and consumer load and at the same time maintaining transient stability of grid.

This paper discusses the control strategies used in wind energy conversion system in both generator side and grid side converter of PMSG generator as per existing grid codes during healthy and fault conditions. Also, the different converter topologies that have been used also discussed and different types of maximum power point tracking techniques are discussed.

\section{MAJOR COMPONENTS OF WECS}

The basic configuration of grid-connected MWWECS is depicted in Fig. 1. The WECS is composed of several components that convert wind kineticenergy into electric energy in a controlled, reliable and efficient manner. The major components of a WECS can be broadly classified as mechanical, electrical and control systems. The mechanical components include tower, nacelle, rotor blades, rotor hub, gearbox, pitch drives, yaw drives, wind speed sensors, drive-train, and mechanical brakes. The electrical components include electric generator, possible power electronic converter along with generator- and grid-side harmonic filters, step-up transformer and three-phase grid or collection-point. The control related components are used with both the mechanical and electrical energy conversion systems.
The most visible parts in the large wind turbines are tower, nacelle and rotor blades, and rest of the components are housed inside the wind turbine [10].

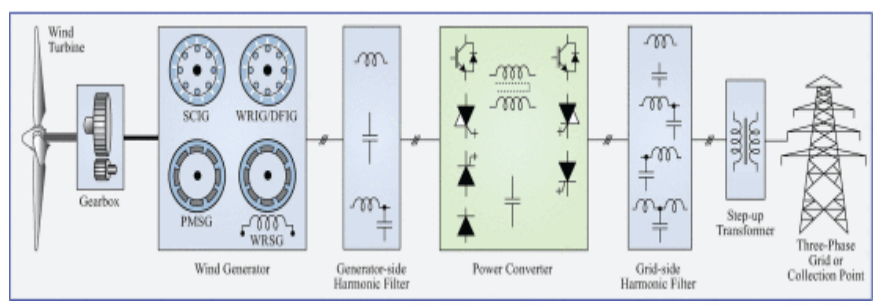

Fig. 1. Basic configuration of a grid-connected megawatt wind turbine.

\section{A. Mechanical Components}

The wind kinetic-energy is first converted to mechanical-energy with the help of airfoil-shaped rotor blades. For the current MW wind turbines, threebladed design is most efficient and common [11,12] The tower, nacelle and rotor hubs provide mechanical support to the rotor blades. The kinetic to mechanical energy conversion efficiency depends on many factors such as the shape of rotor blades, angle of blades, wind speed velocity, air density, etc.. The wind velocity and direction are measured with the help of sensors, and a yaw drive is used to move the rotor blades along with nacelle towards the wind to extract the maximum possible energy. As per the aerodynamic properties, any particular turbine generates maximum electricity at or above the rated wind speed only. When the wind speed is more than the rated value, the angle of blades is changed such that the electric power output is limited to the rated value [13]. The MW wind turbines usually run at very low speed (typically 6-20 rpm) and high torque.

To couple the low-speed, high-torque wind turbine shaft with the high-speed, low-torque generator shaft, a multistage gearbox is used. A three-stage gearbox containing one planetary stage and two helical stages is usually employed in high-speed generators.

\section{B. Elecrical Components}

An electric generator is used to convert rotational mechanical-energy into electric-energy. Over the past 30 years, many generators such as the squirrel-cage induction generator (SCIG), wound rotor induction generator (WRIG), doubly-fed induction generator (DFIG), permanent magnet synchronous generator (PMSG) and wound rotor synchronous generator (WRSG) have been developed for wind turbines [14]. 
The first generation of wind turbines were based on SCIG only, but the present generation turbines incorporates both induction and synchronous generators. The induction generators (IGs) usually operate at high rotational speeds, while the synchronous generators (SGs) can operate at low, medium, or high speeds. In order to achieve lower operational speed, the generator needs to be equipped with a large number of poles, which is a feasible solution with SG's. In accommodating the large number of poles, the stator radius becomes 6 times larger and 4.5 times heavier compared to the threestage gearbox based induction generators [15].

The generator output voltage and frequency change with respect to the wind speed. The generator can be directly coupled to the grid or it can be interfaced through a power electronic converter. By arranging the power switching devices in different ways, possibly with the dc-link elements such as capacitors or inductors, numerous power converter topologies can be derived. The harmonic filter on the generatorside helps to reduce harmonic distortion of the generator currents and voltages. This leads to a reduction in harmonic losses incurred in the generator's magnetic core and winding. The harmonic filter in the grid-side converter helps to meet strict harmonic requirements specified by the grid codes.

\section{Control System}

The wind turbine system also consists of several slave control systems for the mechanical/electrical components and a master control system (not shown in Fig. 1) to achieve desired dynamic and steady-state performance for the WECS. The controller usually monitors various variables such as wind speed velocity, wind direction, generator voltages/currents, filter/dc-link voltages if any, grid voltages and currents, and adjusts the system operating states or variables at the reference value or in the set boundaries [16]. For example, when the wind speed is more than the rated value, the master control system initiates passive stall, active stall or pitch control systems to respond and change the angle of blades such that the turbine output power can never exceed the rated value. The control systems have been with limited functions in the first generation of wind turbines, and now they perform large number of functions with respect to the turbine, generator and power converter operation, grid integration, protection standards, and wind farm operation [17].

\section{CONTROL STRATEGIES USED IN PMSG BASED WECSS}

The incorporation of advanced control systems into WECS is one of the major technological advances together with improvements in materials, power electronics and blade designs. In many studies, the researchers have attempted to develop a variety of control strategies for PMSG based WECS so as to come up with such a system which is simple, reliable, robust, and has the ability to handle intolerable disturbances those might occur during its operation. Different control issues in small-PMSG based WECS were surveyed in [18].

\section{A) Pitch angle control}

The pitch angle control is a mechanical way of controlling the rotor blade angle of the WT so as to regulate the output power of the same. Most of the major WT manufacturers are now developing new MW scale VSWTs based on PMSGs with pitch angle control so as to protect the WT from over power and over torque conditions due to sudden wind gusts at higher wind speeds. The pitch angle is usually fixed at lower wind speeds. On the contrary, at high wind speeds, the pitch angle control is activated to shed off the aerodynamic power by turning the rotor blades through some angle from the direction of striking wind. In accordance with the variation of wind speed, strategies for turbine pitch angle control and rotational velocity control are developed in [19]. Neural network and fuzzy logic control are employed in [20] to improve the performance. Pitch angle control may become complicated due to the non-linear aerodynamic characteristics of the WT. In view to that, a simple and robust pitch control technique, which can tolerate turbine parameter uncertainties and non-parametric perturbations, is reported in [21].

\section{B) Control of machine-side /grid-side converters}

Two most dominant strategies classified under vector control viz. field-oriented control (FOC) and direct torque control (DTC) are used at the machine-side and have almost similar dynamic responses. The FOC is one of the most established strategies for generator speed control which involves dual loop control structure - an outer speed control loop and an inner current control loop usually based either on hysteresis control in natural reference frame or on PI control in synchronous reference frame. In FOC, the electromagnetic torque is controlled through q-axis component of the stator current and the d-axis stator current is forced to be zero so as to get the maximum 
electromagnetic torque with minimum stator current. Since, the current is controlled directly; the line currents of the machine contain low harmonics which in turn leads to high efficiency.

\section{C) Maximum power point tracking (MPPT)}

Corresponding to each wind speed, there is a specific generator speed which yields the maximum possible wind power. Beyond this specific generator speed, the power extracted from the wind subsequently reduces. Operating WT in variable-speed mode, optimum energy extraction from the wind can be achieved. For the reason, many different MPPT control strategies such as optimum relationship-based (ORB) control, tip-speed ratio (TSR) control, optimal torque control (OTC) and perturb and observe (P\&O)/ hill-climb search (HCS) control have been developed during the last few decades.

\section{D) Optimum relationship-based (ORB) control}

The ORB control is a mature MPPT strategy in which wind speed measurement is not required and the response to wind speed change is fast. ORB control ensures MPPT using a precalculated look-up table which is structured with the aid of knowledge of optimum relationships among various system parameter; for instance, the power versus shaft speed, the power versus torque, the power versus rectified dc-link voltage and the dc-link voltage and dc-side current. The ORB control is simple to implement, has good dynamic response, requires no wind speed sensor, can produce smoother output power when compared with the other strategies and is widely used in commercial WECSs.

The main drawback of ORB control is that system pre-knowledge is a requisite, which varies from one system to the other and may even change with the system aging. Furthermore, ORB control may require lots of memory space.

\section{DIFFERENT CONFIGURATIONS OF POWER CONVERTERS IN WECS}

The general overview of power converters, technical requirements for power converters in WECS and classification of power converters for WECS are addressed in this section.

The general classification of power converters which are more relevant to the wind energy application is shown in Fig. 2. The objective of the power converters is to enable variable-speed operation in Type 3 and 4 WECS, while eliminating the need for soft-starter and reactive power compensation. To enable the grid connection of these wind turbines, the variable voltage/frequency of the wind generator should be converted to fixed voltage/frequency. To accomplish this, a wide variety of power conversion stages can be employed as summarized in Fig. 2. Most of the power conversion stages have found commercial applications, and some have been proposed in literature with promising features for future development.

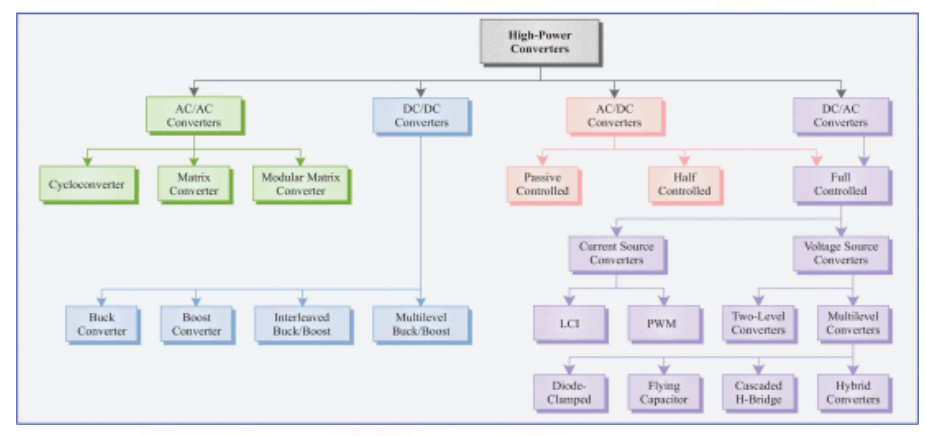

Fig. 2. General classification high power converters.

The converter topologies are broadly classified as direct and indirect according to the power conversion performed. The direct conversion uses single-stage ac/ac converters, while indirect conversion uses twostage $(\mathrm{ac} / \mathrm{dc}+\mathrm{dc} / \mathrm{ac}) \quad$ or three-stage $(\mathrm{ac} / \mathrm{dc}+\mathrm{dc} / \mathrm{dc}+\mathrm{dc} / \mathrm{ac})$ conversion. Some of these converters are adopted from the electric drives industry, while some other are solely developed for wind power application. The direct ac/ac converters and current source converters are also shown in the classification because they are main competitors to the voltage source converters in the electric drives industry. The successful converters from the electric drive industry are also presented even though they have not been used in wind industry yet.

The power converters in the first generation of wind turbines (Type 1) were used for smooth grid connection only. They are disconnected from the circuit once the turbine is tied to the grid. But the modern Type 3 and 4 WECS demand the power converters to meet several technical and operational requirements. The most important requirements are listed below:

> Initial Cost: This factor has prime importance in achieving low cost of energy (COE) and competing with other energy sources. The initial cost of power converter is only a fraction (approximately 7\%$12 \%$ ) of overall wind turbine cost. Though it is a small part, huge cost savings can be accomplished 
for a wind farm which consists of hundreds of wind turbines.

\section{Reliability, Modularity and Maintenance Cost:} In addition to the initial cost, the maintenance cost (replacement cost for components and salary for technicians) must also be very less to achieve low COE. According to the latest reports on wind turbine faults, the electric generators and power converters are on the top of list with an average failure rate of $13 \%-20 \%$. The power converter faults increase the downtime of wind turbine operation, and overall cost of energy. For this reason, the power converters for wind turbines, especially offshore turbines must have high reliability. The power converters having a modular structure are preferable because even one power converter fails, the wind turbine can still work with reduced capacity, and thus the downtime can be mitigated.

Efficiency: At MW power level, efficiency is an important factor in reducing COE. Even $1 \%$ improvement in the efficiency of power converter can save millions of dollars at the wind farm level, which consists of hundreds of power converter based wind turbines. The power losses which directly affect the efficiency should be minimized by using highly efficient switching devices, optimal arrangement of switching devices (also called power converter topology), cooling system, modulation/control schemes, etc.

$>$ Power Quality: The power quality can be attributed to various parameters of power converter. The output voltage waveform must be close enough to sinusoidal waveform. This is also described as number of steps in the output voltage waveform $(\mathrm{dv} / \mathrm{dt})$. As the number of steps in the waveform increases, the $\mathrm{dv} / \mathrm{dt}$ decreases and thus the requirement for output filter also decreases. Moreover, the electromagnetic interference becomes lower as $\mathrm{dv} / \mathrm{dt}$ decreases. The total harmonic distortion (THD) of generator and grid currents must be lower to decrease generator shaft oscillations and to feed quality currents to the grid, respectively.

Grid Code Compliance: It is one of the important requirements for the grid-connected $\mathrm{MW}$ wind turbines. The power converters must feed currents to grid with low THD (less than 5\%), provide reactive power whenever requested by the grid operator, ride-through during grid faults, and provide voltage/frequency support among other requirements. These requirements must be accomplished by the power converter itself, without requesting support from the external hardware/components such as STATCOM or FACTS.

An ideal power converter must possess all the above features. In practice it is impossible to design a power converter embedding all the above technical merits. The engineering approach would be to satisfy most crucial requirements while sacrificing the least important conditions. A best-selling power converter obviously incorporates most of the above features for wind turbines.

\section{CONCLUSIONS}

In this paper, a comprehensive review of high-power wind energy systems is presented with main focus on electrical technologies. Efficient utilization of wind energy has been an important issue. As a result, VSWT systems with the power electronics interfaces have increasingly drawn the interest of WT manufacturers. It is possible to increase the controllability of the WTs with the use of power electronics, which is a major concern for their integration into the power grid. Among the most popular concepts in the current VSWTs, the PMSG is the one which provides a realistic opportunity to realize the gearless operation, and is considered as a potential candidate for new designs in high power WT applications. Recently, the cost reduction and advancements in the permanent magnet materials have made them even more attractive than before. In this review, the mainstream power converter topologies used for PMSG based WTs were systematically reviewed with a clear focus to their features and limitations.

Also different control strategies which can be used for extracting the power from the wind are also discussed. As the power converters are the one of the major components of the WECS, so special emphasis is given to this and what are the requirement of ideal power converter are discussed.

The future will see enormous growth of wind energy systems in the world. Technological development of wind energy conversion systems will play a major role in making wind power systems highly efficient. Switching to wind power will ensure energy independence and pollution free environment. The oil 
is expensive, but wind is free-now and forever, and for every nation.

\section{REFERENCES}

[1] Blaabjerg F, Chen Z. "Power electronics as an enabling technology for renewable energy integration". J Power Electron 2003;3:81-9.

[2] Blaabjerg F, Chen Z, Kjaer SB. "Power electronics as efficient interface in dispersed power generation systems". IEEE Trans Power Electron 2004;19:118-94 I.S. Jacobs and C.P. Bean, "Fine particles, thin films and exchange anisotropy," in Magnetism, vol. III, G.T. Rado and H. Suhl, Eds. New York: Academic, 1963, pp. 271-350.

[3] Md., Rabiul Islam Y, Guo, Zhu J. "A review of offshore wind turbine nacelle: technical challenges, and research and developmental trends". Renew Sustain Energy Rev 2014;33:16176.

[4] $\mathrm{Li} \mathrm{H}$, Chen $\mathrm{Z}$. "Overview of different wind generator systems and their comparisons". IET Renew Power Gener 2008;2(2):123-38.

[5] Wang Zheng, Yuwen Bo, Lang Y, Cheng Ming. "Improvement of operating performance for the wind farm with a novel CSC-type wind turbineSMES hybrid system". IEEE Trans Power Deliv 2013;28(2):693-703.

[6] Singh Mukhtiar, Chandra Ambrish. "Application of adaptive network-based fuzzy inference system for sensorless control of PMSG-based wind turbine with nonlinear-load compensation capabilities". IEEE Trans Power Electron 2011;26(1):165-75.

[7] Chen Z, Spooner E. "Grid interface options for variable speed permanent magnet generators". IEE Proc Electr Power Appl 1998;145:273-83.

[8] Orlando NA, Liserre M, Mastromauro RA, Dell'Aquila A. "A survey of control issues in PMSG-based small wind-turbine systems". IEEE Trans Ind Inf 2013;9:1211-21.

[9] Chen Z, Spooner E. "Grid power quality with variable speed wind turbines”. IEEE Trans Energy Convers 2001;16:148-54.

[10] R. Thresher, M. Robinson, and P. Veers, "To capture the wind,' IEEE Power Energy Mag., vol. 5, no. 6, pp. 34-46, Nov. 2007.

[11] J. K. Kaldellis and D. Zafirakis, "The wind energy (r)evolution: A short review of a long history,' Int. J. Renew. Energy, vol. 36, no. 7, pp. 1887-1901, 2011.

[12] The Portal of Wind Turbines and Models, Wind turbines, May 2014. [Online]. Available: http://en.wind-turbine-models.com.

[13] Offshore Turbine Database, 4 C Offshore, May 2014. [Online]. Available: http://www. 4coffshore.com.

[14] T.-F. Chan and L.-L. Lai, "Permanent-magnet machines for distributed power generation: A review,' in Proc. IEEE Power Energy Soc. (PES) Gen. Meet., Tampa, FL, USA, Jun. 2007, pp. 1-6.

[15] ] M. Liserre, R. Cardenas, M. Molinas, and J. Rodri'guez, 'Overview of multi-MW wind turbines and wind parks," IEEE Trans. Ind. Electron., vol. 58, no. 4, pp. 1081-1095, Apr. 2011.

[16] V. Yaramasu, "Predictive control of multilevel converters for Megawatt wind energy conversion systems," Ph.D. dissertation, Ryerson Univ., Toronto, ON, Canada, 2014.

[17] A. Miller, E. Muljadi, and D. Zinger, "A variable speed wind turbine power control,' IEEE Trans. Energy Convers., vol. 12, no. 2, pp. 181-186, Jun. 1997.

[18] Orlando NA, Liserre M, Mastromauro RA, Dell'Aquila A. "A survey of control issues in PMSG-based small wind-turbine systems". IEEE Trans Ind Inf 2013;9 (3):1211-21.

[19] Yin M, Li GY, Zhang JC. "Modeling and control strategies of directly driven wind turbine with permanent magnet synchronous generator". Power Syst Technol 2007;31(15):60-5.

[20] Chedid R, Mrad F, Basma M. "Intelligent control of class of wind energy conversion systems". IEEE Trans Energy Convers 1999;14:1597-604.

[21] Geng H, Yang G. "Output power control for variable-speed variable pitch wind generation systems". IEEE Trans Energy Convers 2010;25(2):494-503. 